\title{
Submucosal tunneling endoscopic resection for seven esophageal leiomyomas
}

A 47-year-old man came to our hospital with half a year's history of chest discomfort. An upper gastrointestinal endoscopy detected seven protruding lesions distributed in a dispersed fashion on different areas of the esophageal walls ( Fig. 1), about $23-32 \mathrm{~cm}$ from the incisors. Endoscopic ultrasound (EUS) revealed the tumors to be originating from the muscularis propria layer, without any malignant features (> Fig.2). Although he was told that a "wait and see" approach could be taken at first, the patient requested active treatment.

Given our previous success in creating a tortuous tunnel to resect two contralateral esophageal leiomyomas [1], submucosal tunneling endoscopic resection (STER) was performed. A longitudinal mucosal incision was made on the axis where most of the tumors were located, $3 \mathrm{~cm}$ above the most proximal one. A submucosal tunnel was created, and the first tumor was revealed. The second one was not aligned with the first, so could not be directly reached by a straight tunnel; therefore, a tortuous tunnel was created. Methylene blue was injected at the site of the second tumor, indicating the tunnel route, and the two tumors were identified ( $\triangleright$ Fig. 3 a). We then repeated

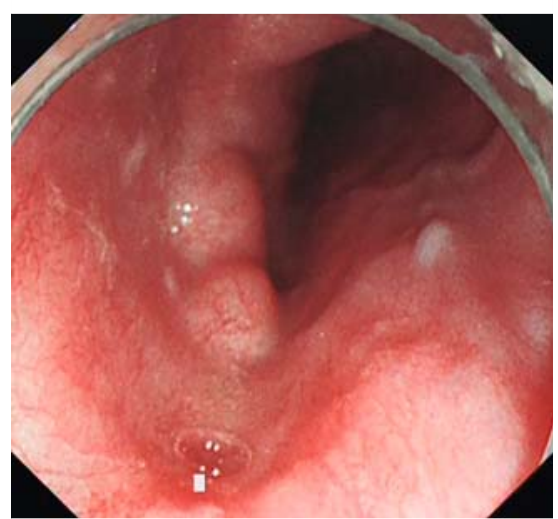

- Fig. 1 Endoscopic image showing three protruding lesions (tumors number 5,6 , and 7).

the submucosal injection and tunneling procedure from the oral side to the anal side, and identified the seven tumors one by one. All of the tumors were then clearly exposed. Meticulous resection was performed with an insulated-tip knife (IT knife), and all of the tumors were dissected off the muscularis propria layer ( Fig. $\mathbf{3}$ b, c). Visible blood vessels were coagulated, and the mucosal entry site was closed (\Video 1 ).

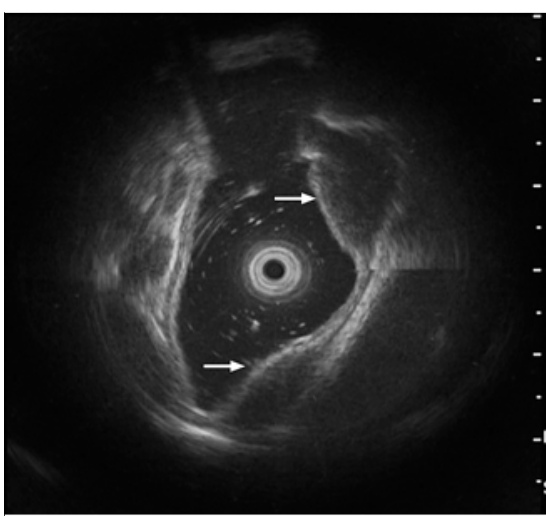

Fig. 2 Endoscopic ultrasound (EUS) image showing two hypoechoic masses originating from the muscularis propria layer, with no malignant features evident.

The procedure took 190 minutes and there were no adverse events. The diameter of the largest tumor was $1.8 \mathrm{~cm}$ and all of the tumors were leiomyomas histopathologically ( $>$ Fig.4). The patient did not complain of further chest discomfort during the 3-month follow-up period, and no recurrence was noticed.

Endoscopy_UCTN_Code_TTT_1AO_2AG
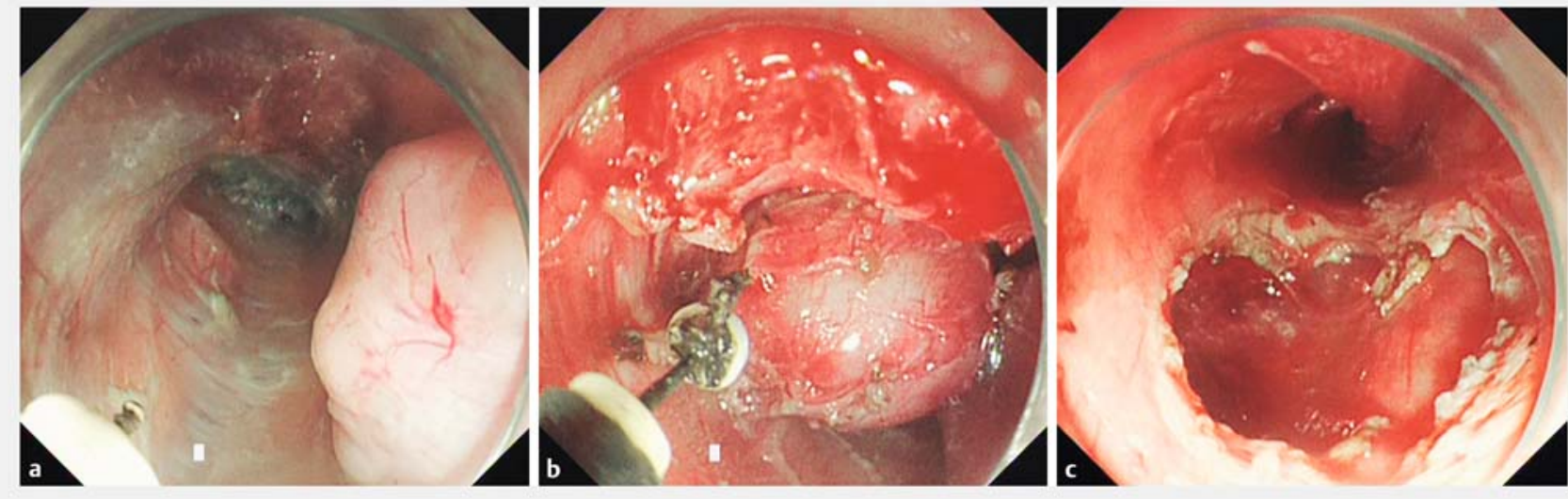

- Fig. 3 Endoscopic images showing: a two tumors (numbers 1 and 2 ) in one submucosal tunnel; $\mathbf{b}$ dissection of one of the tumors using an insulated-tip knife; $c$ the wound surface after removal of the tumor. 


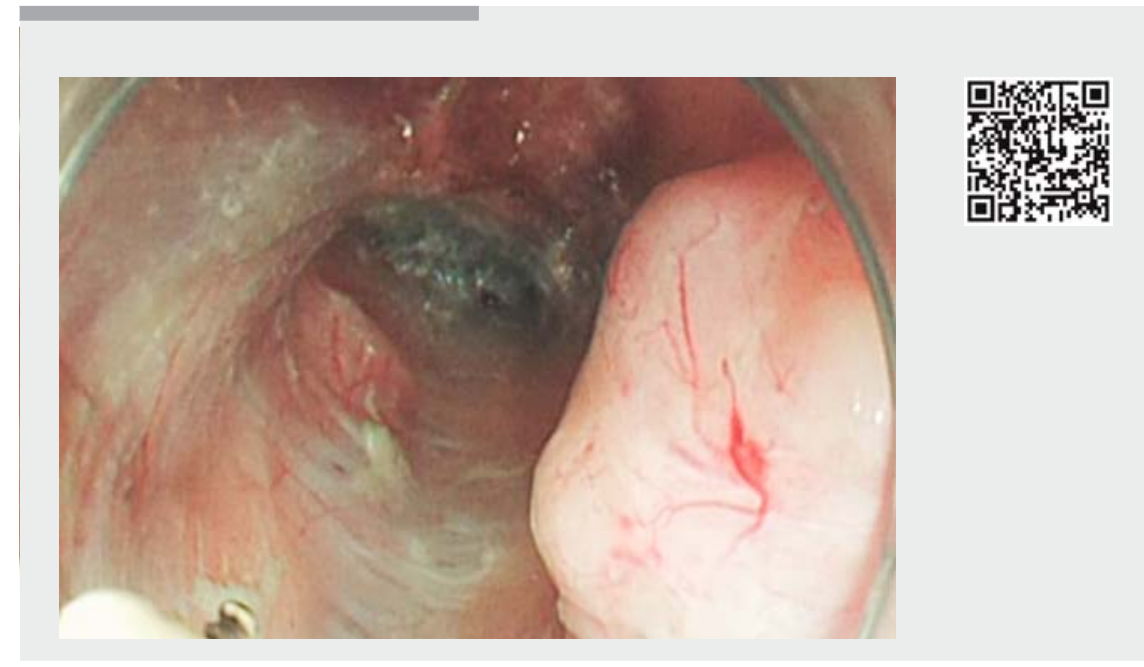

Video 1 Endoscopic appearance of seven esophageal submucosal tumors, and the procedure for their resection by the submucosal tunneling endoscopic resection (STER) technique.

\section{Competing interests}

None

The authors

\section{Xiaoyu Tang, Yuyong Tan, Liang Lv, Deliang}

Liu

Department of Gastroenterology, The Second Xiangya Hospital of Central South University, Changsha, Hunan, China

\section{Corresponding author}

\section{Deliang Liu, MD}

Department of Gastroenterology, The Second Xiangya Hospital of Central South University, NO. 139 Middle Renmin Road, Changsha, Hunan, 410011, China Fax: +86-0731-85533525

deliangliu@csu.edu.cn

\section{Reference}

[1] Zhou F, Tan Y, Chu Y et al. Submucosal tunneling endoscopic resection for leiomyomas located on opposite esophageal walls: the role of a tortuous submucosal tunnel. Endoscopy 2016; 48: E255 - E226

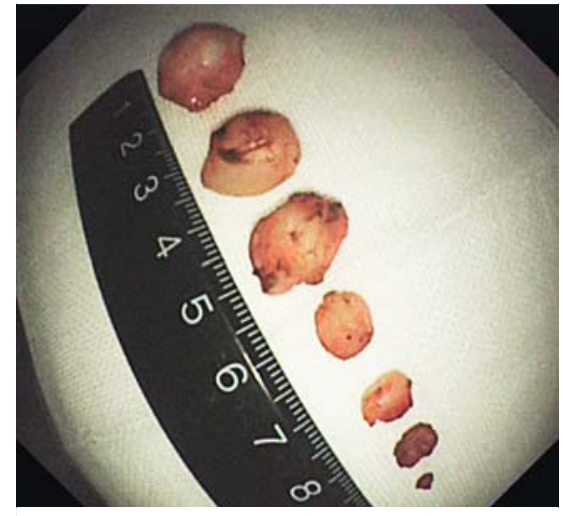

-Fig. 4 Macroscopic appearance of the seven resected specimens.

\section{Bibliography}

DOI https://doi.org/10.1055/s-0043-123821

Published online: 15.12.2017

Endoscopy 2018; 50: E59-E60

(c) Georg Thieme Verlag KG

Stuttgart · New York

ISSN 0013-726X

\section{ENDOSCOPY E-VIDEOS}

https://eref.thieme.de/e-videos

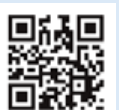

Endoscopy E-Videos is a free access online section, reporting on interesting cases and new

techniques in gastroenterological endoscopy. All papers include a high quality video and all contributions are freely accessible online.

This section has its own submission website at

https://mc.manuscriptcentral.com/e-videos 